\title{
Dynamic Industrial System Approach to the Industrial Sustainability Development Based on National Economy - With a Case of Taiwan
}

\section{Hsiao-Fan Wang* and Du Lin}

Department of Industrial Engineering and Engineering Management, National Tsing Hua University, Hsinchu, Taiwan

\begin{abstract}
As human beings living in the so-called "blue planet," our main responsibility lies in protecting the earth and its resources. The exhaustion of petrochemical energy and the greenhouse effect have caused huge impact on our lives. With these in mind, specifically their damage to the environment and the economy, this study discusses the possible strategies used in dealing with the industrial sustainability issues from a national viewpoint.

A Dynamic Industrial System (DIS) is proposed in which the integration of the input-output analysis with the time series analysis is developed. Scenario analysis for energy conservation and carbon reduction is conducted to facilitate the strategy development of the industrial sectors.

The case of the Taiwan economy is adopted to illustrate the proposed system. The proposed DIS is applied by classifying all domestic industries into nine sectors. Then, the vector time series analysis is carried out to predict the related input and output factors up to the year 2025. By observing the development trend of each focal industry sector included in this work with the analysis of the degree of industrial influence and sensitivity, the scenario analysis regarding the energy saving and carbon emission reduction are carried out to observe the changes in the industrial input to the impact and development of the output as consequence. Thus, the proper industrial strategies are developed to support a government on approaching a win-win frontier of both the environment and the economy.
\end{abstract}

Keywords: Sustainability development; Input and output analysis; Time series analysis; Dynamic industrial system; Scenario analysis; Taiwan economy

\section{Introduction}

Recently, reserves for non-renewable forms of energy such as coal, petroleum and natural gas have rapidly decreased. Thus, the exhaustion of fossil energy has become a global environmental issue. The greenhouse effect caused by excessive carbon emissions has also become a global crisis, and is projected to further affect the daily human life in the future. Therefore, the sustainable development has become an urgent issue that must be addressed.

Taiwan is a small island country which is located in the seismic zone with rare energy resources. Analysis of the possible developments of the national economy as well as the inter-relation between industries facilitates the development of effective industrial policies for supporting the Taiwan government. Thus, the current research has two main objectives: a) to develop a dynamic system for investigating the industrial development in a national scale and, b) to propose the possible policies for sustaining the industrial economy of Taiwan.

In order to investigate the overall structure of the industrial sectors, the input-output analysis based on the national surveyed input-output tables is adopted. By incorporating the vector time series analysis, Dynamic Industrial System (DIS) is then proposed and established, with the case of Taiwan as an example. By observing the trend of industrial development in the scenarios concerning energy conservation and carbon reduction, this research provides suggestions to the government to attain the win-win situation involving the environment and industrial economy.

The remainder of this article is organized as follows. In Section 2, literature related to the issues of sustainability development, inputoutput analysis, and time series analysis are reviewed and discussed.
In Section 3, the DIS is proposed and the scenario analysis for environmental goals of energy conservation and carbon reduction is conducted. In Section 4, the Taiwan case is used as an example. The influence and sensitivity analysis and the scenario analysis are also provided. The conclusions of this article, suggesting directions for future studies, are presented in Section 5.

\section{Literature Review}

The world economy has rapidly grown in the last century. In relation to this, the consumption of natural resources has become a critical issue, especially in light of the rapidly depleting natural resources, including non-renewable forms of energy and petrochemicals. With the development of the manufacturing sectors throughout the world, the levels of carbon emission have also become higher, thus causing serious greenhouse effect that damages the environment to a great extend. Previous studies have already covered this issue from many aspects, including energy consumption, economy, environmental impact and biological systems, to name a few.

Related issues and possible strategies to achieve sustainable development are discussed in Section 2.1. Then, based on the macro economy viewpoint, possible approaches developed in the literature

*Corresponding author: Hsiao-Fan Wang, Department of Industrial Engineering and Engineering Management, National Tsing Hua University101, Sec. 2, KuangFu Road, Hsinchu, Taiwan, E-mail: hsiaofanwang@gmail.com

Received July 11, 2013; Accepted August 21, 2013; Published August 26, 2013

Citation: Wang HF, Lin D (2013) Dynamic Industrial System Approach to the Industrial Sustainability Development Based on National Economy-With a Case of Taiwan. Ind Eng Manage 2: 118. doi: 10.4172/2169-0316.1000118

Copyright: @ 2013 Wang HF, et al. This is an open-access article distributed under the terms of the Creative Commons Attribution License, which permits unrestricted use, distribution, and reproduction in any medium, provided the original author and source are credited. 
to analyze a global industrial system are reviewed in Section 2.2. To develop sustainable strategies for future development, the existing methods for time series analysis are discussed in Section 2.3.

\section{The issues of sustainability development}

To cope with issues of sustainable development, many viewpoints and approaches have been considered. The issue covers many aspects, including energy crisis, carbon emission, economic development, dynamic situation in the future, and strategies to achieve sustainability.

The Canadian economist, William [1] and his student, Wackernagel [2], have proposed the method called Ecological Footprints (EF) to measure the sustainability of an ecological system. The method determines the total amount of biologically productive land and water area that a population requires to produce the resources it consumes and absorb the waste it generates. However, the approach simply recognizes whether or not Sustainability development can be achieved; it does not consider the economic and environmental indices, such as GDP and carbon emission. As a static model, it also cannot help find ways to ensure sustainable development in the future.

Chang et al. [3] have combined the input-output table and the concept of green GDP to construct a new model. The study discussed the industrial strategies proposed and attempted to identify the industries that must be pushed to achieve economic development, while considering the impacts of such strategies on the environment. However, data on the green GDP in Taiwan are very rare; moreover, the model is also static and cannot analyze the impact of strategies implemented in the future. Then, Wei et al. [4] have modeled a framework that combined system dynamics and EF to discuss urban sustainability. The model provides a dynamic EF framework to analyze the situation. It is affected by many factors and set different policy scenarios to discuss the policy's feasibility and sustainability. This model also overcomes the disadvantages of the static EF method. Nevertheless, the scale of this approach is too large. From the macro viewpoint, the model has many assumptions between relations of variables and does not provide specific industrial strategies.

In their work, Jerzy et al. [5] have used five variables: $M$ (nonrenewable mineral), $\mathrm{R}$ (renewable resource), $\mathrm{K}$ (production capital), $\mathrm{Q}$ (abatement capital), and $\mathrm{H}$ (human capital) to describe the visual relations between natural resources and human development along a time horizon to achieve sustainability. The proposed model is dynamic; thus, by changing the parameters, the authors found ways to achieve environmental and economic development. However, the model merely indicates that global sustainability development is possible. It still does not provide measurable strategies related to the changing parameters in their study.

As mentioned previously, there are several viewpoints and approaches concerning the dilemma of sustainable development. Given that, this study aims to discuss the sustainable development problem from the viewpoint of industrial strategies based on the inputoutput analysis as discussed below.

\section{Input and output analysis}

Input-output analysis was first proposed by Leotief et al. [6] in 1936. The economic activities and interactions among different industrial sectors in one country are analyzed based on the structure of the input-output relation tables. Nowadays, many governments use the input-output table ( $\mathrm{I} / \mathrm{O}$ table) to develop industrial strategies and national policies.

The input-output table includes all industries with many sectors, each representing one aggregated production as shown in Figure 1. According to different utilization purposes, the input-output analysis is normally presented in three forms: Product Transaction Table, Input Coefficient Table, and Degree of Relation Table. The Product Transaction Table describes all transactions as well as the industrial inputs of the original and those of others. The unit used is thousand dollars. The Input Coefficient Table is also called cost coefficient or technology coefficient. It represents the ratio of one-unit sector's input compared with that of every other sector. In other words, it shows the intermediate demand of one sector for all other sectors to produce one unit of the product. The Degree of Relation Table is also called the Leontief Inverse Matrix, which represents the interdependence among the industrial sectors.

The input-output analysis provides an economic viewpoint to analyze the economy of a nation and the industrial relations. Haimes and his team have published a number of articles related to the inputoutput analysis, for instance, Haimes and his team at the Center of for Risk Management of Engineering Systems, University of Virginia have developed a number of theories and applications on the input-output

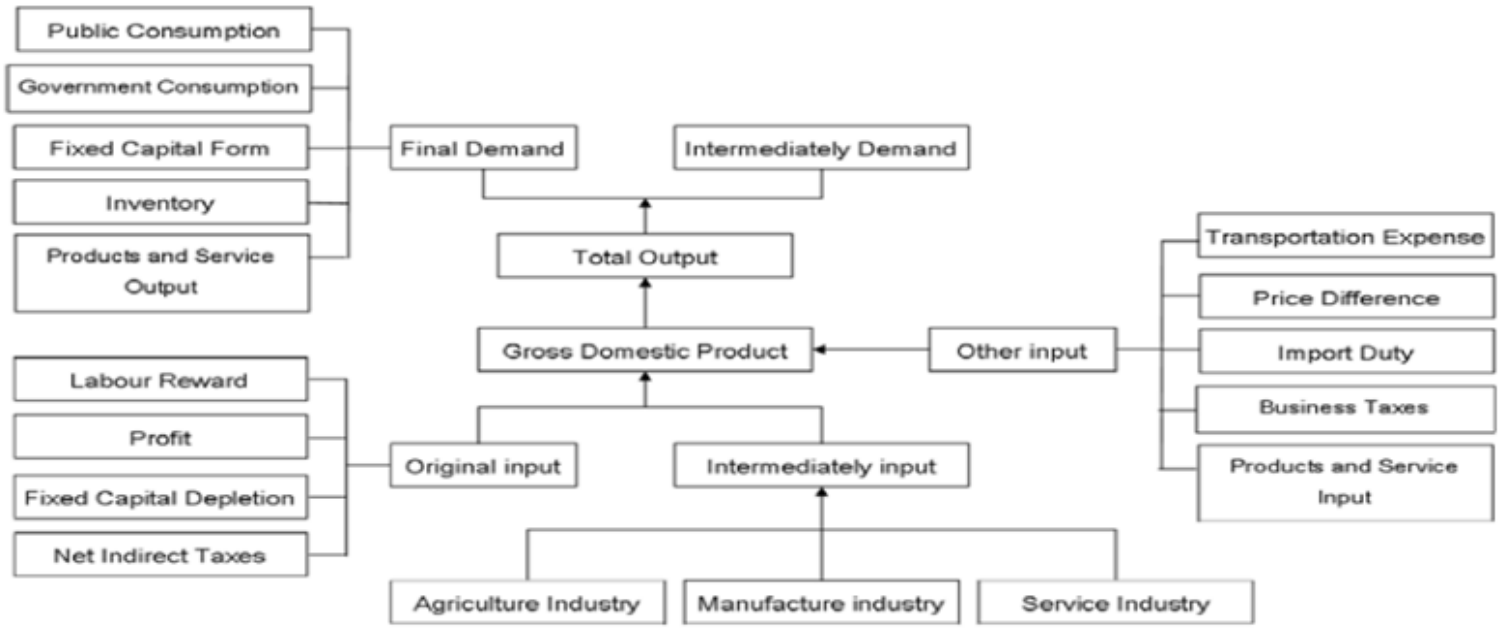

Figure 1: The structure of input-output table. 
analysis, which have not only shown the inoperability of input-output table from the national scale to international scale or regional scale $[7,8]$. But also the applicability of evaluation on the resource supplies [9]. However, the input-output model is static; thus, it is unable to represent the situation of development in the future. Therefore, how to base on the input-output tables to develop a forecasting model is an issue we shall investigate in this study.

However, because the input-output tables are established from general survey on the national industries and business, the operational cost is too high to conduct frequently, which leads to the lack of sufficient tables for statistical analysis. Therefore, how to make the best use of the existing tables for forecasting is another issue we study in this study.

\section{Time series analysis}

Time series analysis uses past data to determine the trend of data in the future. This method assumes that the trend of development in the future can be traced from the past. The common time series models include Autoregressive Model (AR), Moving Average Model (MA), Mixed Autoregressive-Moving Averge Model (ARMA), and Vector Autoregressive Model (VAR) [8-10].

Because the models of AR, MA and ARMA are point-estimation in nature, yet input-output tables are in vector to represent all industries in interests. Therefore, we shall focus on the discussion of the features and development of VAR $(p)$ model.

Basically, utilizing VAR $(p)$ in this study can be outlined below [11] (i) it describes and predicts the trend of macroeconomics along time series data. (ii) it describes the cause-effect relation of macroeconomics, helping the decision maker analyze the policy from a macroeconomic viewpoint.

In forecasting a vector, in which the variables are related, the VAR $(p)$ model is generally defined in (1) below.

$$
y_{t}=c_{0}+\phi_{1} y_{t-1}+\phi_{2} y_{t-2}+\ldots \ldots .+\phi_{p} y_{t-p}+\varepsilon_{t}
$$

Where $y_{t}$ is a vector, $\varphi_{p}$ is a relational matrix, $c_{0}$ is a coefficient vector, and parameter $p$ denotes the previous $p$ periods.

If there are too few data to apply $\operatorname{VAR}(p)$, model $\operatorname{ARMA}(p, q)$ can be adopted in the form as below.

$$
y_{t}=c_{0}+\sum_{i=1}^{p} \alpha_{i} y_{t-i}+\varepsilon_{t}+\sum_{i=1}^{q} \beta_{i} \varepsilon_{t-i}
$$

Where $y_{t}$ is a time series data with time $t, c_{0}$ is the constant, $\alpha_{i}$ is the coefficient of $y_{t-i}, \beta_{i}$ is the coefficients of $\varepsilon_{t-i}$ and $\varepsilon_{t}$ are the residuals.

\section{Methodology of the Proposed Dynamic Industrial System}

In order to develop the proper industrial strategy to achieve energy conservation and carbon reduction, a model called Dynamic Industrial System (DIS) is proposed to describe the relations of national industries along the time horizon. The system contains three parts: input-output analysis, time series analysis, and scenario analysis. While the time series analysis provides a tool to forecast the states of input-output relations of all industries in the future, the input-output analysis paves a way to observe the relations among the national industries. With the scenario analysis, the strategies to achieve the different environmental and economic goals, particularly those on energy conservation and carbon reduction, are determined.

\section{The proposed Dynamic Industrial System (DIS)}

To cope with the dynamic feature of national sustainable development, this section introduces the approaches based on the reviewed literature. First, it is noted that the traditional input-output analysis is a static approach based on the national industrial survey. Consequently, two features are observed: (1) it only analyzes data from the past; and (2) the input-output tables (I/O tables) summarized from the national industrial statistics do not evenly distribute over time, thus resulting in the bias on trend analysis. Therefore, it is necessary to integrate the suitable tools of time series analysis into the input-output analysis in order to observe the continuous changes of input-output structures among the industries, as well as to predict the input-output table in the future. With such dynamic features, the DIS is proposed in this section.

Let us first define some notations used in DIS:

$X_{i}^{t}$ : The gross domestic product of $i^{\text {th }}$ industry at year $t, i=1 \sim n$.

$Z_{i j}^{t}$ : The intermediate demand of the $i^{\text {th }}$ industry from $j^{\text {th }}$ industry at year $t, i, j=1 \sim n$.
$F_{i}^{t}$ : The final demand of the ith industry at year $t, i=1 \sim n$
$O_{i}^{t}$ : The other input of ith industry at year $t, i=1 \sim n$.

First, the equilibrium of demand-supply of the national economy along the time horizon, $t$, is described in (3) below:

$$
\left[\begin{array}{c}
X_{1} \\
\vdots \\
X_{n}
\end{array}\right]^{t}+\left[\begin{array}{c}
O_{1} \\
\vdots \\
O_{n}
\end{array}\right]^{t}=\left(\begin{array}{ccc}
Z_{11} & \cdots & a_{1 n} \\
\vdots & & \vdots \\
Z_{n 1} & \cdots & Z_{m n}
\end{array}\right)\left[\begin{array}{c}
1 \\
\vdots \\
1
\end{array}\right]+\left[\begin{array}{c}
F_{1} \\
\vdots \\
F_{n}
\end{array}\right]^{t}
$$

This is transformed into (4), by defining $a_{i j}^{t}=Z_{i j}^{t} / X_{j}^{t}$ as the number of $i^{\text {th }}$ products needed to produce one unit $j^{\text {th }}$ product at year $t$.

$$
\left[\begin{array}{c}
X_{1} \\
\vdots \\
X_{n}
\end{array}\right]^{t}+\left[\begin{array}{c}
O_{1} \\
\vdots \\
O_{n}
\end{array}\right]^{t}=\left(\begin{array}{ccc}
a_{11} & \cdots & a_{1 n} \\
\vdots & & \vdots \\
a_{n 1} & \cdots & a_{n n}
\end{array}\right)^{t}\left[\begin{array}{c}
X_{1} \\
\vdots \\
X_{n}
\end{array}\right]^{t}+\left[\begin{array}{c}
F_{1} \\
\vdots \\
F_{n}
\end{array}\right]^{t}
$$

Rewriting (4) into the matrix form in (5)

$$
X_{n \times 1}^{t}+O_{n \times 1}^{t}=A_{n \times 1}^{t} X_{n \times 1}^{t}+F_{n \times 1}^{t}
$$

we can obtain

$$
X_{n \times 1}{ }^{t}=(I-A)^{-1}{ }_{n \times n}^{t}\left(F_{n \times 1}-O_{n \times 1}\right)^{t}
$$

The backward effect means that the influence on other industries is caused by the $j^{\text {th }}$ industry's final demand change in one unit.

$$
B L_{j}=\sum_{i=1}^{n} b_{i j}
$$

After normalizing the backward effect, the degree of influence is obtained as following:

$$
R B_{j}=\sum_{i=1}^{n} b_{i j} / \frac{1}{n} \sum_{i=1}^{n} \sum_{j=1}^{n} b_{i j}
$$

Greater than the average; on the other hand, if $R B_{j}<1$, the degree of influence of the $j^{\text {th }}$ industry is smaller than the average.

The forward effect represents the influence on the $i^{\text {th }}$ industry when every industry's final demand changes one unit.

$$
F L_{i}=\sum_{j=1}^{n} b_{i j}
$$

After normalizing the forward effect, the degree of sensitivity is obtained as following: 


$$
R F_{i}=\sum_{j=1}^{n} b_{i j} / \frac{1}{n} \sum_{i=1}^{n} \sum_{j=1}^{n} b_{i j}
$$

On one hand, if $R F_{i}>1$, then the degree of sensitivity of the $i^{\text {th }}$ industry is greater than the average; On the other hand, if $R F_{i}>1$, the degree of sensitivity of the $i^{\text {th }}$ industry is smaller than the average. The overall influence of industries is then analyzed using the backward and forward effects.

\section{Time series analysis in DIS}

To cope with the time parameter in model (6), adoption of $\operatorname{VAR}(p)$ is proposed for forecasting the input-output relations of (6) at any year t. The aggregation procedures of the $\operatorname{VAR}(p)$ model is introduced in Section 3.2.1. Because the $\operatorname{VAR}(p)$ model requires a large amount of data to perform adequate time series analysis, if there are not sufficient data, the $\operatorname{ARMA}(p, q)$ model is suggested to forecast the data in the vector individually. The aggregation procedures of $\operatorname{ARMA}(p, q)$ model are introduced in Section 3.2.2.

The VAR $(p)$ model: To cope with the time parameter in model (6), adoption of $\operatorname{VAR}(p)$ is proposed for forecasting the input-output relations of (6) at any year t. The procedure of applying $\operatorname{VAR}(p)$ is shown in Figure 2 and step-by-step illustration is followed.

\section{Step 1: Stationary Check}

In order to ensure that the sequence of the data is stable over time, we first check whether or not the data is stationary. For time series data to be considered stationary,

it has to meet three conditions listed below [11] (Ender, 2004).

$$
\begin{aligned}
& \text { (a) } E\left(y_{t}\right)=E\left(y_{t}-k\right)=u \\
& \text { (b) } \operatorname{Var}\left(y_{t}\right)<\infty \\
& \text { (c) } \operatorname{Cov}\left(y_{t}, y_{t-k}\right)=E\left(y_{t}-u\right)\left(y_{t-k}-u\right)
\end{aligned}
$$

If the time series data are stationary, this means that the data can be anticipated; otherwise, the time series data have to be transformed by, for instance, taking the log or the difference. The stationary test employs

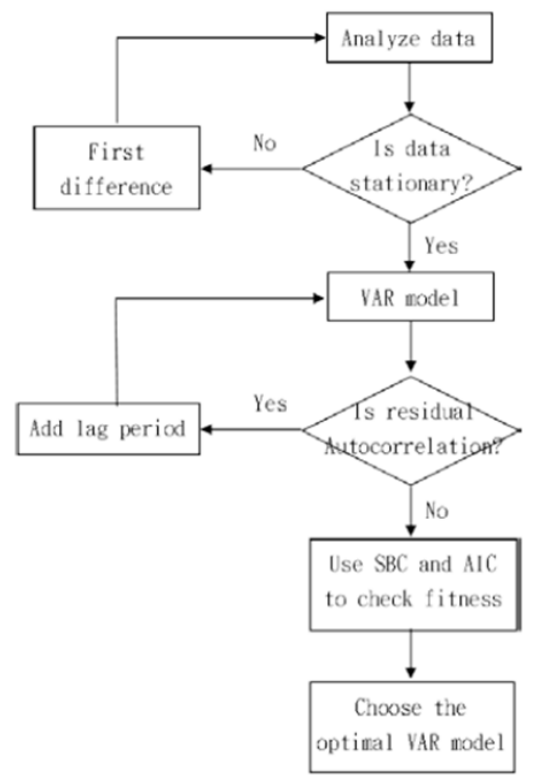

Figure 2: The Flow Chart of VAR Analysis. several methods, such as the Dickey-Fuller test, Augmented DF test, and KPSS test. Because the KPSS test [12] assumes a deterministic trend with a random walk variable, and an error consisting of the properties of the data, the KPSS test is adopted for our stationary test. The Lagrange Multiplier (LM) statistics proposed by Kwiatkowski with the null hypothesis of non-stationary data is shown below.

$$
L M=\sum_{t=1}^{T} S_{t}^{2} / \sigma_{\varepsilon}^{2}
$$

If the time series data is non-stationary, we should take the log or difference to stabilize the data trend, and then go back to check again.

Step 2: Determination of the Required Periods $p$

Different VAR models with different lag periods $p$ are constructed. In this step, the statistic software Gretl (Copyright () 2000-2010 Allin Cottrell and Riccardo "Jack" Lucchettii) is applied to help us construct the $\operatorname{VAR}(p)$ model.

\section{Step 3: Check on Auto-correlation of Residuals}

The residuals of the $\operatorname{VAR}(p)$ model are checked by determining whether or not they are auto-correlated; if they are, this is resolved, for instance, by adding a lag period. By adopting the Ljung-Box Q test [13], the auto-correlation coefficient of the $i^{i t}$ period is defined as

$$
\rho(i)=\frac{\sum_{t=i+1}^{T} \hat{\varepsilon_{t}} \varepsilon_{t-1}}{\sum_{t=1}^{T} \hat{\varepsilon_{t}}}
$$

where $T$ is the number of the samples.

By substituting (14) into Ljung-Box Q statistic, we have

$$
Q(p)=T(T+2) \sum_{i=1}^{s} \rho(i)^{2} /(T-i)
$$

where $s=1,2,3 \ldots$ means $p$ degrees of freedom.

The null hypothesis is that the variable is non-autocorrelation from 1 to $s$ periods.

Step 4: Fitness Comparison with Different $\operatorname{VAR}(p)$ Models

Once the $\operatorname{VAR}(p)$ model is constructed, the Schwarz Bayesian Information Criterion (SBC) Enders [14] is checked for the fitness of the model and the Akaike Information Criterion (AIC). SBC and AIC are statistic indexes that measure the error of the fitness degree, as defined below.

$$
\begin{aligned}
& S B C=T \ln (S S E)+k \ln (T) \\
& A I C=T \ln (S S E)+2 k
\end{aligned}
$$

SSE: sum of square error T: the number of sample

$k$ : the number of estimated parameter

From the definitions, these two indexes are affected by the sum of square error and the number of estimated parameter. The higher are the sum of the square error and the number of estimated parameter, the larger are the SBC and AIC values, then the lower the degree of fitness is. Therefore, the $\operatorname{VAR}(p)$ model with low SBC and AIC values has been developed.

\section{Step 5: Determination of the Best Model}

Based on the above, an optimal $\operatorname{VAR}(p)$ model with the lowest SBC and AIC is chosen.

The ARMA $(p, q)$ model: If the data are insufficient or the results 
of the $\operatorname{VAR}(p)$ model lose the trend of data, the $\operatorname{ARMA}(p, q)$ model shown in (2) is adopted to predict each scalar datum. The operational procedure of $\operatorname{ARMA}(\mathrm{p}, \mathrm{q})$ is shown in Figure 3 with step-by-step illustration.

\section{Step 1: Stationary Check}

The process of checking whether or not the data are stationary is the same as that used in the VAR model. The conditions for data to be stationary are the same as those shown in (11) to (13). If the data are stationary, we go to the next step.

Step 2: Determination of the Required Periods $p$ and $q$ by ACF and PACF

After checking whether or not the data are stationary, we used both the Auto-Correlation Function (ACF) and the Partial AutoCorrelation Function (PACF) Yang [15] to set the lag periods $p$ and $q$. The ACF represents the correlation of the s lag period in the past time series data. The auto-correlation function of period $s$ is defined as:

$$
\rho(s)=\frac{\operatorname{cov}\left(y_{t}, y_{t-s}\right)}{\operatorname{cov}\left(y_{t}, y_{t}\right)}
$$

The PACF represents the influence of the s period in the time series data, such as the influence of $y_{t-s}$ on yt. From the time series regressions shown in (20) to (23) of a time series $y_{t}$, the PACF can be clearly realized.

$$
\begin{aligned}
& y_{t}=\varphi_{1,0}+\varphi_{1,1} y_{t-1}+v_{1} \\
& y_{t}=\varphi_{2,0}+\varphi_{2,1} y_{t-1}+\varphi_{2,2} y_{t-2}+v_{2 t} \\
& y_{t}=\varphi_{3,0}+\varphi_{3,1} y_{t-1}+\varphi_{3,2} y_{t-2}+\varphi_{3,3} y_{t-3}+v_{3 t} \\
& y_{t}=\varphi_{j, 0}+\varphi_{j, 1} y_{t-1}+\varphi_{j, 2} y_{t-2}+\ldots \ldots+\varphi_{j, j+1)} y_{t \cdot-j-1}+\varphi_{j, j} y_{t-j}+v_{j t}
\end{aligned}
$$

The PACF of the $s$ period on the time series data is:

$$
\varphi(s)=\varphi_{i j}, j=s
$$

The rule of the partial auto-correlation function of the s period is defined in (25 27) below [14]:

$$
\begin{aligned}
& \varphi(s)=\rho(s), s=1 \\
& \varphi(s)=\frac{\left[\rho(1)-\rho(2)^{2}\right]}{\left[1-\rho(1)^{2}\right]}, s=2
\end{aligned}
$$

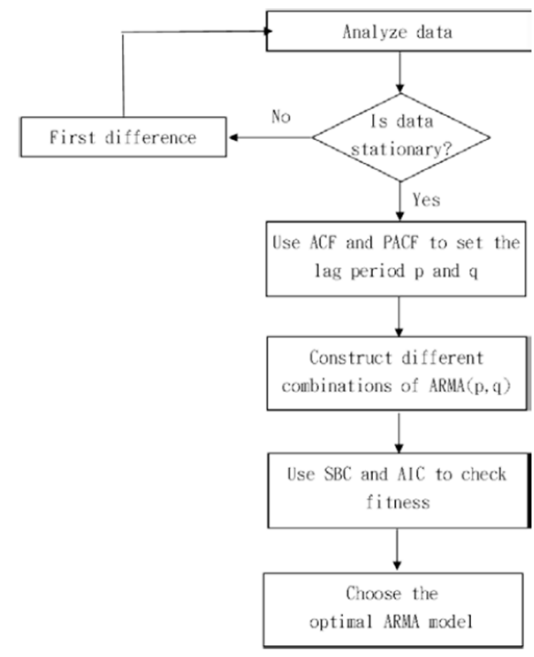

Figure 3: The Flow Chart of $\operatorname{ARMA}(p, q)$.

$$
\varphi(s)=\frac{\rho_{s}-\sum_{j=1}^{s-1}\left(\varphi_{s-2, j}-\varphi_{s s} \varphi_{s-2, s-j}\right) \rho_{s-j}}{1-\sum_{j=1}^{s-1}\left(\varphi_{s-2, j}-\varphi_{s s} \varphi_{s-2, s-j}\right) \rho_{j}} \text { for } s \geq 3
$$

Using the information form ACF and PACF, the parameters $p$ and $q$ are decided.

\section{Step 3: Establishment of the Models}

At this point, we construct the different combinations of $\mathrm{p}$ and $\mathrm{q}$ that have been set up in step 2. The statistic software, Gretl (Copyright (C) 2000-2010 Allin Cottrell and Riccardo "Jack" Lucchettii), is used to help construct the model.

\section{Step 4: Fitness Comparison of Different VAR $(p)$ Models}

The indexes of SBC and AIC are used to measure the error of the fitness degree. The SBC and AIC are the same as those in the formula (17) and (18)

\section{Step 5: Determination of the Best Model}

The best combination of $p$ and $q$ with the lowest SBC and AIC values is chosen.

Scenario analysis by DIS: After combining the input-output analysis and the time series analysis, the information in (6) at any year $t$ is obtained. Therefore, the industrial structure with the concerned scenarios is analyzed. Referring to the industrial degrees of influence and sensitivity, as shown in (8) and (10), the scenario analysis is developed and conducted based on the properties revealed from the forecasted input-output table in interest. From the influence and sensitivity analysis, the importance of industries and the static quality of industries are realized. Thus, the industries to be promoted are revealed, along with the rates of manufacture with respect to the service for different scenarios.

To ensure sustainability, scenarios regarding the environmental impacts, such as energy conservation and carbon reduction, must be addressed so that the feasibility and specificity of environmental goals can be evaluated. In our study, three scenarios are drawn to simulate the different situations to attain the goals of environmental improvement in the future. Based on this scenario analysis, we shall propose the industrial strategies to achieve a win-win situation in the environment and economy in the future.

Based on International Energy Summit conducted in Copenhagen in 2009, three scenarios are drawn in Table 1 for analysis of the case of Taiwan as an example.

\section{Illustrative Case of Taiwan}

The proportion of imported fossil energy exceeds $99 \%$ in Taiwan, making it a high energy-dependent country. The shortage of petrochemical energy resources greatly affects the industrial development of Taiwan. Moreover, the impact of carbon emissions to the environment, brought about by the global use of petrochemical energy, has also become another critical issue. Thus, energy saving and carbon reduction have become international movements.

To observe the rate of energy usage and impact to the national industries in Taiwan, we apply the DIS to the industrial structure of this country. We initially collected and classified data to establish the $\mathrm{I} / \mathrm{O}$ tables in Section 4.1. Then, based on these I/O tables, time series analysis is applied in Section 4.2 to forecast the items of the other 
input, final demand and intermediate demand of every industry in the desired year. Furthermore, using the Leontief Inverse, we analyzed the Industrial influence and performed the sensitivity analysis in Section 4.3. Finally, in Section 4.4, we consider the possible scenarios to support the government in policy making, so that its environmental and economic goals can be achieved.

\section{Data analysis and classification}

Based on the information of domestic industries provided by the Directorate-General of Budget, Accounting and Statistics, Executive [16], we collected 11 Product Transaction Tables for the years 1981, 1984, 1986, 1989, 1991, 1994, 1996, 1999, 2001, 2004, and 2006.

For the purposes of investigating the industries of energy resources, the changes in GDP and the sensitivity of industries, all industries are classified into nine sectors as following Table 2, It can be noted that sectors (I2), (I3) and (I8) are related to the energy industries, of which Sector (I2) refers to industries specializing in non-renewable natural sources of energy, such as petrochemical and natural gas; Sector (I3) represents the metal resource industries; and Sector (I8) mainly represents the industries generating electricity and water supply. Sector (I5) represents the industries manufacturing products from nonrenewable fossil resources [17].

Given that the surveyed data are not equally spaced, which means that the data are not available by each yearly interval, the Weighted Average Method is applied to fill the missing data from formulae (28).

$$
y_{t}=\frac{d_{i}}{d_{i}+d_{j}} y_{i}+\frac{d_{j}}{d_{i}+d_{j}} y_{j}
$$

where $y_{t}$ is the missing data to be estimated in between two given adjacent data, $y_{i}$, and $y_{i}$; and $y_{i} y_{j}$ are the yearly distances from $y_{i}, y_{j}$ to

\begin{tabular}{|c|c|c|c|}
\hline Scenario & Scenario 1 & Scenario 2 & Scenario 3 \\
\hline Goal & Business as usual & $\begin{array}{c}\text { Energy conservation } \\
\text { Bureau of Energy, } \\
\text { Ministry of Economic } \\
\text { Affairs, Sustainable } \\
\text { energy police } \\
\text { convention, 2008. }\end{array}$ & $\begin{array}{c}\text { Carbon reduction } \\
\text { Ministry of Economic } \\
\text { Affairs, National } \\
\text { energy conservation } \\
\text { and carbon reduction } \\
\text { program, 2010. }\end{array}$ \\
\hline Description & $\begin{array}{c}\text { Follow the } \\
\text { same policy } \\
\text { from the past. }\end{array}$ & $\begin{array}{c}\text { Promote government } \\
\text { organization to } \\
\text { conserve Electronic } \\
\text { and fossil energy and } \\
\text { to reduce 7\% by 2015. }\end{array}$ & $\begin{array}{c}\text { The level of carbon } \\
\text { emission returns to } \\
\text { 2005 at year 2020 and } \\
\text { returns to 2000 at year } \\
2025 .\end{array}$ \\
\hline Techniques & $\begin{array}{c}\text { Time series } \\
\text { analysis }\end{array}$ & $\begin{array}{c}\text { Influence and } \\
\text { Sensitivity Analysis }\end{array}$ & $\begin{array}{c}\text { Influence and } \\
\text { Sensitivity Analysis }\end{array}$ \\
\hline
\end{tabular}

Table 1: Description of the Scenario.

Industrial sectors

(I1)Agricultural industries

(I2)Petrochemical and nature gas mining industries

(I3)Metal and other mining industries

(14) Food-processing, textile, tannery, fur product wood products, paper product, pesticides and chemical product industries

(I5) Petroleum product, coal product, plastics and balata industries

(I6) Metal and non-metal product industries

(I7) Electronic parts, computer, electronic, optic product power equipment, mechanical equipment, transportation, furniture, mechanical repairmen industries

(I8) Electric and fuel gas supply water supply industries

(I9) Service construction industries

Table 2: Classification of Taiwan Industries. $y_{t}$ respectively. From the above, we then obtain the evenly distributed input-output tables from 1981 to 2006.

\section{Forecast of industrial structure}

From (6), we forecast the other input, the final demand and the intermediate demand in the I/O tables. For the other input, we apply the $\operatorname{VAR}(p)$ model to forecast the other input and as illustrated in Figure 2. However, when we apply $\operatorname{VAR}(p)$ to the final demand and intermediate demand, the limited data cannot represent the real trend of the time series data. Therefore, we apply the $\operatorname{ARMA}(p, q)$ model shown as Figure 3 , to predict the final demand and intermediate demand. With the intermediate demand, we transform it into the Input Coefficient Table and the Leotief inverse matrix [18].

After forecasting the data of the other input, the final demand and input coefficient table, the structures of demand and supply in the years of 2010, 2015, 2020 and 2025 are summarized in Table 3.

From Table 3, it can be noted that while the GDP increases from $28,554,915.0$ in 2006 to $90,946,162.2$ in 2025 , the ratio of GDP descends gradually from $79.03 \%$ to $66.18 \%$, respectively. On the other hand, the ratio of the other input increases gradually from $20.97 \%$ to $33.82 \%$. This shows that in order to satisfy the demands, products need to be imported from abroad, in particular the fossil energy that Taiwan cannot sufficiently produce [19].

Meanwhile, the ratio of intermediate demand decreases gradually from $45.88 \%$ to $33.33 \%$, whereas the ratio of final demand increases from $54.12 \%$ to $66.67 \%$. Hence, the efficiency of using energy increases gradually. The number of products that are as intermediate inputs becomes less, while goods for consumption rise.

For detailed analysis, the GDP and the ratio of each industry are tabulated in Table 4:

From Table 4, we can observe that the total GDPs increase along with the years $2006,2010,2015,2020$, and 2025. Additionally, the ratio of GDP of service construction industries (I9) rises from $48.19 \%$ to $61.39 \%$, whereas he ratios for other industries have not significantly changed. This trend emphasizes that the service industries would be the main economic industries in the future. The profit generated by the service industries is also very large. In addition, we can observe that the trends of most industries in terms of GDP grow stably except the petrochemical and nature gas mining industries (I2) of petrochemical and nature gas mining industries. Specifically, the GDP of (I2) rises from 20,976 to $988,599.7$ in 2015 , descends to $204,530.4$ in 2020 , and rises again to $755,843.1$ in 2025 . This implies the unstable output of the fossil mining industry [20].

Furthermore, in order to conduct the scenario analysis on national scale, further aggregation of the industry sectors into the three major industrial sectors as agriculture (I1), manufacturing (I2-I8) and service (I9) is shown in Table 5, which provides bases for our scenario analysis.

\section{Analysis of industrial influence and sensitivity}

In order to analyze the degrees of influence and sensitivity of all future industries that we predicted, from the Leontief Inverse Matrix, we apply (8) and (10) to calculate the degrees of influence and sensitivity in 2006, 2010, 2015, 2020, and 2025. For comparison, those of the given data in the last year of 2006 and the furthest forecast year in 2025 are tabulated in Table 6 and the respective degrees of the industries in 2025 are plotted in Figure 4. 
Citation: Wang HF, Lin D (2013) Dynamic Industrial System Approach to the Industrial Sustainability Development Based on National Economy-With a Case of Taiwan. Ind Eng Manage 2: 118. doi: 10.4172/2169-0316.1000118

Page 7 of 10

\begin{tabular}{|c|c|c|c|c|c|c|c|c|c|c|}
\hline & \multicolumn{2}{|c|}{2006} & \multicolumn{2}{|c|}{2010} & \multicolumn{2}{|c|}{2015} & \multicolumn{2}{|c|}{2020} & \multicolumn{2}{|c|}{2025} \\
\hline & $\begin{array}{c}\text { Amount of } \\
\text { money }\end{array}$ & Ratio & $\begin{array}{c}\text { Amount of } \\
\text { money }\end{array}$ & Ratio & $\begin{array}{c}\text { Amount of } \\
\text { money }\end{array}$ & Ratio & $\begin{array}{c}\text { Amount of } \\
\text { money }\end{array}$ & Ratio & $\begin{array}{c}\text { Amount of } \\
\text { money }\end{array}$ & Ratio \\
\hline GDP(1) & 28554915.0 & $79.03 \%$ & 38642694.7 & $78.03 \%$ & 51739728.6 & $74.73 \%$ & 64739441.1 & $69.49 \%$ & 90946162.2 & $66.18 \%$ \\
\hline Other input(2) & 7576839.0 & $20.97 \%$ & 10879233.6 & $21.97 \%$ & 17492050.6 & $25.27 \%$ & 28417658.0 & $30.51 \%$ & 46475006.0 & $33.82 \%$ \\
\hline $\begin{array}{c}\begin{array}{c}\text { Supply=Demand } \\
(1)+(2)=(3)+(4)\end{array}\end{array}$ & 36131754.0 & $100.0 \%$ & 49521928.3 & $100.0 \%$ & 69231779.2 & $100.0 \%$ & 93157099.1 & $100.0 \%$ & 137421168.2 & $100.0 \%$ \\
\hline $\begin{array}{l}\text { Intermediate } \\
\text { demand(3) }\end{array}$ & 16578391.0 & $45.88 \%$ & 20429206.5 & $41.25 \%$ & 23423912.1 & $33.83 \%$ & 30637753.3 & $32.89 \%$ & 45799106.3 & $33.33 \%$ \\
\hline Final demand(4) & 19553363.0 & $54.12 \%$ & 29092721.9 & $58.75 \%$ & 45807867.1 & $66.17 \%$ & 62519345.8 & $67.11 \%$ & 91622062.0 & $66.67 \%$ \\
\hline
\end{tabular}

Table 3: The Predicted Industrial Structure of Taiwan (unit: million).

\begin{tabular}{|c|c|c|c|c|c|c|c|c|c|c|}
\hline & \multicolumn{2}{|c|}{2006} & \multicolumn{2}{|c|}{2010} & \multicolumn{2}{|c|}{2015} & \multicolumn{2}{|c|}{2020} & \multicolumn{2}{|c|}{2025} \\
\hline & GDP & ratio & GDP & ratio & GDP & ratio & GDP & ratio & GDP & ratio \\
\hline 11 & $451,227.0$ & $1.58 \%$ & $516,328.9$ & $1.34 \%$ & $519,682.0$ & $1.00 \%$ & $543,620.8$ & $0.84 \%$ & $683,785.1$ & $0.75 \%$ \\
\hline 12 & $20,976.0$ & $0.07 \%$ & $211,475.4$ & $0.55 \%$ & $988,599.7$ & $1.91 \%$ & $266,882.5$ & $0.41 \%$ & $755,843.1$ & $0.83 \%$ \\
\hline 13 & $75,980.0$ & $0.27 \%$ & $228,481.6$ & $0.59 \%$ & $177,726.3$ & $0.34 \%$ & $204,530.4$ & $0.32 \%$ & $244,802.0$ & $0.27 \%$ \\
\hline 14 & $1,750,701.0$ & $6.13 \%$ & $1,802,544.5$ & $4.66 \%$ & $1,683,198.2$ & $3.25 \%$ & $1,857,587.7$ & $2.87 \%$ & $2,474,095.1$ & $2.72 \%$ \\
\hline 15 & $3,171,769.0$ & $11.11 \%$ & $3,806,510.6$ & $9.85 \%$ & $4,346,270.3$ & $8.40 \%$ & $4,623,046.5$ & $7.14 \%$ & $6,520,560.9$ & $7.17 \%$ \\
\hline 16 & $2,720,331.0$ & $9.53 \%$ & $3,253,464.8$ & $8.42 \%$ & $2,117,356.9$ & $4.09 \%$ & $3,919,772.3$ & $6.05 \%$ & $5,249,467.1$ & $5.77 \%$ \\
\hline 17 & $5,893,187.0$ & $20.64 \%$ & $7,687,645.8$ & $19.89 \%$ & $9,976,467.5$ & $19.28 \%$ & $13,241,356.9$ & $20.45 \%$ & $17,538,288.1$ & $19.28 \%$ \\
\hline 18 & $710,479.0$ & $2.49 \%$ & $846,442.1$ & $2.19 \%$ & $980,415.6$ & $1.89 \%$ & $1,159,682.8$ & $1.79 \%$ & $1,649,697.7$ & $1.81 \%$ \\
\hline 19 & $13,760,265.0$ & $48.19 \%$ & $20,289,800.9$ & $52.51 \%$ & $30,950,012.2$ & $59.82 \%$ & $38,922,961.0$ & $60.12 \%$ & $55,829,623.2$ & $61.39 \%$ \\
\hline total GDP & $28,554,915$ & $100.00 \%$ & $38,642,694.7$ & $100.00 \%$ & $51,739,728.6$ & $100.00 \%$ & $64,739,441.1$ & $100.00 \%$ & $90,946,162.2$ & $100.00 \%$ \\
\hline
\end{tabular}

From Table 4, we can observe that the total GDPs increase along with the years 2006,

Table 4: The Predicted GDPs of the Concerned Industry Sectors (unit: million).

\begin{tabular}{|c|c|c|c|c|c|c|c|c|c|c|}
\hline \multirow{2}{*}{} & \multicolumn{2}{|c|}{$\mathbf{2 0 0 6}$} & \multicolumn{2}{|c|}{$\mathbf{2 0 1 0}$} & \multicolumn{2}{|c|}{$\mathbf{2 0 1 5}$} & \multicolumn{2}{|c|}{$\mathbf{2 0 2 0}$} \\
\cline { 2 - 10 } & GDP & ratio & GDP & ratio & GDP & ratio & GDP & ratio & GDP & ratio \\
\hline 11 & $451,227.0$ & $1.58 \%$ & $516,328.9$ & $1.34 \%$ & $519,682.0$ & $1.00 \%$ & $543,620.8$ & $0.84 \%$ & $683,785.1$ & $0.75 \%$ \\
\hline $12 \sim 18$ & $14,343,423.0$ & $50.23 \%$ & $17,836,564.9$ & $46.16 \%$ & $20,270,034.4$ & $39.18 \%$ & $25,272,859.3$ & $39.04 \%$ & $34,432,753.8$ & $37.86 \%$ \\
\hline 19 & $13,760,265.0$ & $48.19 \%$ & $20,289,800.9$ & $52.51 \%$ & $30,950,012.2$ & $59.82 \%$ & $38,922,961.0$ & $60.12 \%$ & $55,829,623.2$ & $61.39 \%$ \\
\hline total & $28,554,915.0$ & $100.00 \%$ & $38,642,694.7$ & $100.00 \%$ & $51,739,728.6$ & $100.00 \%$ & $64,739,441.1$ & $100.00 \%$ & $90,946,162.2$ & $100.00 \%$ \\
\hline
\end{tabular}

Table 5: The Major Industrial Structures of Taiwan over Years.

\begin{tabular}{|c|c|c|c|c|}
\hline & \multicolumn{2}{|c|}{2006} & \multicolumn{2}{|c|}{2025} \\
\hline & RB & RF & RB & RF \\
\hline 11 & 0.8581 & 0.5090 & 0.9517 & 0.5172 \\
\hline 12 & 0.8880 & 1.6341 & 0.8580 & 1.3179 \\
\hline 13 & 0.9178 & 0.6121 & 0.8447 & 0.5632 \\
\hline 14 & 1.0904 & 0.7585 & 1.2241 & 0.8927 \\
\hline 15 & 1.3040 & 1.6123 & 0.9718 & 1.2565 \\
\hline 16 & 1.1932 & 1.1085 & 1.1235 & 1.1097 \\
\hline 17 & 1.1582 & 0.8258 & 1.4005 & 0.9910 \\
\hline 18 & 0.9602 & 0.5695 & 0.9963 & 0.6613 \\
\hline 19 & 0.6300 & 1.3702 & 0.6295 & 1.6906 \\
\hline
\end{tabular}

Table 6: Comparative Degrees of Influence and Sensitivity Between Base Year 2006 and Future Year 2025.

From Figure 4, we may observe the following features with respective to four quadrants:

- The degrees of influence and sensitivity of industries in Quadrant I are greater than 1, indicating that those industries have the potential to promote other industries.

- The degrees of influence and sensitivity of industries in Quadrant II are smaller than 1 and greater than 1, respectively. Thus, industries in Quadrant II can be easily affected by other industries. When other industries grow, the industries in Quadrant II will grow as well.

- The degrees of influence and sensitivity of industries in Quadrant III are smaller than 1 . These industries have low industrial relation and are stable.
- The degrees of influence of industries in Quadrant IV are greater than 1 , while the degrees of sensitivity are smaller than 1 . Those industries have the potential to seriously affect other industries and are important industries.

Furthermore, we can compare the industries we are interested in between 2006 and 2025. The degrees of sensitivity of petrochemical and nature gas mining industries (I2) became smaller which represent the (I2) will be used on the part of final consumption like oil and fuel. Therefore, we can observe that the degrees of influence and sensitivity of petroleum product coal, product plastics and balata industries (I5) become smaller and (I5) is also transformed from Quadrant I to Quadrant II which means the industrial role of (I5) become different. 
The degree of influence and sensitivity of electric and fuel gas supply water supply industries (I8) become higher which means the (I8) become more and more important with the continued exhaustion of petrochemical energy.

\section{Scenario analysis}

Recently, energy conservation and carbon reduction have become the most important goals for national environmental management. Meanwhile, GDP represents the economic situation of a country. In this section, we set three scenarios to analyze the relation between the environment and the economy. Referring to Table 1, the scenario assumptions for Taiwan are presented in Table 7. Apart from the economy development based on Scenario 1 as shown Table 4 and Table 5 , that based on Scenario 2 of energy conservation and carbon reduction of Scenario 3 can be referred to Table 8 and Table 10 respectively; of which the pair wise comparisons with respective to the based policy are analyzed and summarized in Tables 9 and Tables 11 respectively.

In Scenario 2, the GDP of petrochemical mining industries (I2) has to be lifted up to satisfy the national goal. Although the levels of the final demand and the other input of (I2), petroleum and carbon product industries (I5) and electric, fuel gas and water supply industries (I8) have been decreased, to retain the final demand of the national economy, the output of petrochemical and nature gas mining industries (I2) have to be increased. However, decreasing small amounts of the GDP values of metal and other mining industries (I3), petroleum and Carbon Product Industries (I5) and electric, fuel gas and water supply industries (I8) is possible to conserve electric and fossil energy.

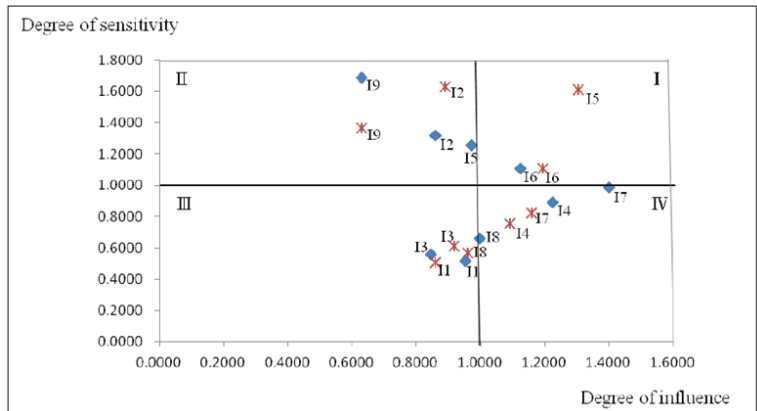

Figure 4: The State and Comparison of Industrial Impacts Between 2006 $(*)$ and $2025(\bullet)$.

\begin{tabular}{|c|c|c|c|}
\hline Scenario & Scenario 1 & Scenario 2 & Scenario 3 \\
\hline Goal & Business as usual & Energy conservation & Carbon reduction \\
\hline Assumption & $\begin{array}{l}\text { The trend of time } \\
\text { series data in } \\
\text { the future will be } \\
\text { related to the data } \\
\text { in the past. }\end{array}$ & $\begin{array}{l}\text { Assumption 1: Based } \\
\text { on classification, } 12,15 \\
\text { and } 18 \text { are the main } \\
\text { industries consuming } \\
\text { electronic and fossil } \\
\text { energy. Assumption } \\
\text { 2: The ratio of the } \\
\text { goal government set } \\
\text { extends to } 2025 \text { year. }\end{array}$ & $\begin{array}{l}\text { Assumption 1: Based } \\
\text { on classification, I2, } \\
14 \sim 17 \text { and I8 are the } \\
\text { main industries } \\
\text { emitting carbon. } \\
\text { Assumption } 2: \text { The } \\
\text { level of carbon } \\
\text { emission returns to } \\
2010 \text { in } 2015 \text { year. }\end{array}$ \\
\hline Application & $\begin{array}{c}\text { Apply the time } \\
\text { series analysis to } \\
\text { forecast the trend } \\
\text { from the data in the } \\
\text { past. }\end{array}$ & $\begin{array}{c}\text { Let the level of final } \\
\text { demand and other input } \\
\text { of } I 2,15 \text { and } I 8 \\
\text { industries reduce } 14 \% \\
\text { accumulated until } 2025 \text {. }\end{array}$ & $\begin{array}{l}\text { Let the level of final } \\
\text { demand and other } \\
\text { input of } I 2,14 \sim 17 \text { and } \\
18 \text { industries return to } \\
2010 \text { in } 2015 \text {, return } \\
\text { to } 2005 \text { in } 2020 \text { year } \\
\text { and returns to } 2000 \\
\text { in } 2025 \text { year. }\end{array}$ \\
\hline
\end{tabular}

Table 7: Content of the Scenarios.
Generally, the total GDP in Scenario 2 is not much altered. In other words, as long as Taiwan can self-sufficiently produce more fossil energy, it can reduce the other input of fossil energy and achieve the goal of energy conservation with the same economic state. Moreover, the degree of energy dependency can be decreased to increase the degree of energy security. However, the fossil resource is rare in Taiwan. Thus, there is a need to increase the efficiency of mining operations or develop a new technology to increase the output of petrochemical mining industries (I2).

In Scenario 3, we can observe that there is a dramatic change in rate. First, the GDPs of agricultural industries agricultural industries (I1) and agriculture-processing product industries (I4) have to be increased. The rate change of petrochemical mining industries (I2) is very large: from $-23.95 \%$ in 2015 to $40.84 \%$ in 2025 , which could be affected by the large variance of petrochemical mining industries (I2) in Scenario 1 that we predicted. In comparison, the output of metal and other Mining Industries (I3), Petroleum and Carbon Product Industries (I5), Metal and Non-Metal Product Industries (I6) and Electric, Fuel Gas and Water Supply Industries (I8) should decrease by approximately $30 \%$ in 2025 . The Electronic Product Industries (I7) and Service Industries (I9) should also decrease their output by $71.03 \%$ and $6.74 \%$ in 2025 , respectively.

In summary, from the decrease of the total GDP from 90,946,162.2 to $70,887,419$, the rate change of GDP is $-22.06 \%$ in 2025 , which implies that the total GDP will decrease yearly by $1.47 \%$ in average.

To sustain economic development, the input should be decreased but increase the output at the same time. In other words, increasing production efficiency is necessary to achieve the goal in Scenario 3.

When we categorize all industries into agriculture (I1), manufacturing (I2-I8) and service (I9) as Table 11, we can observe the industrial structure. In 2025, the output of agricultural increases from $683,785.1$ to $704,653.9$ with a ratio of $0.99 \%$. The output of the manufacturing industry decreases from $34,432,753.8$ to $18,115,318.1$, with a ratio of $25.56 \%$, while the output of the service industry decreases from $90,946,162.2$ to $70,887,419$, with a ratio of $73.45 \%$. Thus, the service industry should be promoted and the manufacturing industry should be regulated to reduce the level of carbon emission.

\section{Conclusion and Future Study}

Due to the shortage of fossil energy and the crises resulting from the greenhouse effect, the issue of sustainability has become an increasingly important and urgent problem which requires immediate solutions. To achieve sustainable environmental and economic development, we propose a methodology for developing the proper industrial polices to gain a win-win situation in a nationwide scale. Due to the inter-relations of industries in the overall national economy, a Dynamic Industrial System (DIS) is developed in this study to analyze the trend of industrial development, with different scenarios of energy conservation and carbon emission in order to provide references for policy making of a government.

In the past, many studies have already placed on the issues of sustainability development. From the viewpoint of industrial strategies and national policies, the input-output analysis is a useful approach. However, based on the statistical input-output tables, the input-output analysis is static and cannot accurately predict the trend of development in the future. In order to investigate the impact of different polices for industrial sustainability, we have applied the time series analysis to 
Citation: Wang HF, Lin D (2013) Dynamic Industrial System Approach to the Industrial Sustainability Development Based on National Economy-With a Case of Taiwan. Ind Eng Manage 2: 118. doi: 10.4172/2169-0316.1000118

Page 9 of 10

\begin{tabular}{|c|c|c|c|c|c|c|c|c|c|c|}
\hline \multirow{2}{*}{} & \multicolumn{2}{|c|}{$\mathbf{2 0 0 6}$} & \multicolumn{2}{|c|}{$\mathbf{2 0 1 0}$} & \multicolumn{2}{|c|}{$\mathbf{2 0 1 5}$} & \multicolumn{2}{|c|}{$\mathbf{2 0 2 0}$} & \multicolumn{2}{|c|}{$\mathbf{2 0 2 5}$} \\
\cline { 2 - 11 } & GDP & ratio & GDP & ratio & GDP & ratio & GDP & ratio & GDP & ratio \\
\hline 11 & $451,227.0$ & $1.58 \%$ & $516,328.9$ & $1.34 \%$ & $519,682.0$ & $1.00 \%$ & $543,620.8$ & $0.84 \%$ & $683,785.1$ & $0.75 \%$ \\
\hline $12 \sim 18$ & $14,343,423.0$ & $50.23 \%$ & $17,829,740.6$ & $46.15 \%$ & $20,271,511.7$ & $39.18 \%$ & $25,285,359.3$ & $39.05 \%$ & $34,465,408.7$ & $37.88 \%$ \\
\hline 19 & $13,760,265.0$ & $48.19 \%$ & $20,289,800.9$ & $52.52 \%$ & $30,950,012.2$ & $59.82 \%$ & $38,922,961.0$ & $60.11 \%$ & $55,829,623.2$ & $61.37 \%$ \\
\hline Total & $28,554,915.0$ & $100.00 \%$ & $38,635,870.5$ & $100.00 \%$ & $51,741,205.8$ & $100.00 \%$ & $64,751,941.1$ & $100.00 \%$ & $90,978,817.1$ & $100.00 \%$ \\
\hline
\end{tabular}

Table 8: Major Industrial Structures Resultant From Scenario 2.

\begin{tabular}{|c|c|c|c|c|c|c|c|c|c|c|c|c|}
\hline Scenario & & Scenario1 & & & & Scen & ario2 & & & Rate o & change & \\
\hline Year & 2010 & 2015 & 2020 & 2025 & 2010 & 2015 & 2020 & 2025 & 2010 & 2015 & 2020 & 2025 \\
\hline 11 & $516,328.9$ & $519,628.0$ & $543,620.8$ & $683,185.1$ & $516,154.3$ & $519,402.0$ & $543,238.8$ & $683,293.4$ & $-0.03 \%$ & $-0.05 \%$ & $-0.07 \%$ & $-0.07 \%$ \\
\hline 12 & $211,475.4$ & $988,599.7$ & $266,882.5$ & $755,843.1$ & $239,711.4$ & $1,052,210.6$ & $381,987.5$ & $942,699.4$ & $13.35 \%$ & $6.43 \%$ & $43.13 \%$ & $24.72 \%$ \\
\hline 13 & $228,481.6$ & $177,726.3$ & $204,530.4$ & $244,802.0$ & $227,443.5$ & $175,888.2$ & $201,929.8$ & $241,764.4$ & $-0.45 \%$ & $-1.03 \%$ & $-1.27 \%$ & $-1.24 \%$ \\
\hline 14 & $1,802,544.5$ & $1,683,198.2$ & $1,857,587.7$ & $2,474,095.1$ & $1,801,780.7$ & $1,681,931.9$ & $1,855,376.1$ & $2,470,787.9$ & $-0.04 \%$ & $-0.08 \%$ & $-0.12 \%$ & $-0.13 \%$ \\
\hline 15 & $3,806,510.6$ & $4,346,270.3$ & $4,623,046.5$ & $6,520,560.9$ & $3,779,714.2$ & $4,302,114.0$ & $4,554,665.6$ & $6,421,227.6$ & $-0.70 \%$ & $-1.02 \%$ & $-1.48 \%$ & $-1.52 \%$ \\
\hline 16 & $3,253,464.8$ & $2,117,356.9$ & $3,919,772.3$ & $5,249,467.1$ & $3,252,186.3$ & 2,115,258.6 & $3,912,469.5$ & $5,236,920.5$ & $-0.04 \%$ & $-0.10 \%$ & $-0.19 \%$ & $-0.24 \%$ \\
\hline 17 & $7,687,645.8$ & $9,976,467.5$ & $13,241,356.9$ & $17,538,288.1$ & $7,688,030.0$ & $9,977,307.8$ & $13,242,587.2$ & $17,538,803.1$ & $0.00 \%$ & $0.01 \%$ & $0.01 \%$ & $0.00 \%$ \\
\hline 18 & $846,442.1$ & 980.415 .6 & $1,159,682.8$ & $1,649,697.7$ & $840,874.4$ & $699,800.4$ & 1,136,343.6 & $1,613,205.9$ & $-0.66 \%$ & $-1.39 \%$ & $-2.01 \%$ & $-2.21 \%$ \\
\hline 19 & $20,289,800.9$ & $30,950,012.2$ & $38,922,961.0$ & $55,829,623.2$ & $20,289,788.1$ & $30,949,832.8$ & $38,922,303.5$ & $55,825,088.3$ & $0.00 \%$ & $0.00 \%$ & $0.00 \%$ & $-0.01 \%$ \\
\hline total & $38,642,694.7$ & $51,739,728.6$ & $64,739,441.1$ & $90,946,162.2$ & $38,635,683.1$ & $51,740,746.5$ & $64,750,901.6$ & $90,973,790.3$ & $-0.02 \%$ & $0.00 \%$ & $0.02 \%$ & $0.03 \%$ \\
\hline
\end{tabular}

Table 9: Comparison between Scenario 1 and Scenario 2.

\begin{tabular}{|c|c|c|c|c|c|c|c|c|c|c|}
\hline \multirow{2}{*}{} & \multicolumn{2}{|c|}{$\mathbf{2 0 0 6}$} & \multicolumn{2}{|c|}{$\mathbf{2 0 1 0}$} & \multicolumn{2}{|c|}{$\mathbf{2 0 1 5}$} & \multicolumn{2}{|c|}{$\mathbf{2 0 2 0}$} \\
\cline { 2 - 9 } & GDP & ratio & GDP & ratio & GDP & ratio & GDP & ratio & GDP & ratio \\
\hline 11 & $451,227.0$ & $1.58 \%$ & $516,328.9$ & $1.34 \%$ & $530,014.8$ & $1.10 \%$ & $578,490.5$ & $1.07 \%$ & $704,653.9$ & $0.99 \%$ \\
\hline $12 \sim 18$ & $14,343,423.0$ & $50.23 \%$ & $17,836,564.9$ & $46.16 \%$ & $17,120,271.4$ & $35.60 \%$ & $16,401,652.5$ & $30.32 \%$ & $18,115,318.1$ & $25.56 \%$ \\
\hline 19 & $13,760,265.0$ & $48.19 \%$ & $20,289,800.9$ & $52.51 \%$ & $30,446,962.7$ & $63.30 \%$ & $37,115,657.9$ & $68.61 \%$ & $52,067,447.0$ & $73.45 \%$ \\
\hline Total & $28,554,915.0$ & $100.00 \%$ & $38,642,694.7$ & $100.00 \%$ & $48,097,248.9$ & $100.00 \%$ & $54,095,800.9$ & $100.00 \%$ & $70,887,419.0$ & $100.00 \%$ \\
\hline
\end{tabular}

Table 10: Major Industrial Structures Resultant from Scenario 3.

\begin{tabular}{|c|c|c|c|c|c|c|c|c|c|c|c|c|}
\hline Scenario & \multicolumn{3}{|c|}{ Scenario1 } & Scenario3 & \multicolumn{4}{|c|}{ Rate of change } \\
\hline Year & 2010 & 2015 & 2020 & 2025 & 2010 & 2015 & 2020 & 2025 & 2010 & 2015 & 2020 & 2025 \\
\hline 11 & $516,328.9$ & $519,682.0$ & $543,620.8$ & $683,785.1$ & $516,328.9$ & $530,014.8$ & $578,490.5$ & $704,653.9$ & $0.00 \%$ & $1.99 \%$ & $6.41 \%$ & $3.05 \%$ \\
\hline 12 & $211,475.4$ & $988,599.7$ & $266,882.5$ & $755,843.1$ & $211,475.4$ & $751,875.7$ & $547,332.6$ & $1,064,525.5$ & $0.00 \%$ & $-23.95 \%$ & $105.08 \%$ & $40.84 \%$ \\
\hline 13 & $228,481.6$ & $177,726.3$ & $204,530.4$ & $244,802.0$ & $228,481.6$ & $157,163.7$ & $141,664.7$ & $151,651.5$ & $0.00 \%$ & $-11.57 \%$ & $-30.74 \%$ & $-38.05 \%$ \\
\hline 14 & $1,802,544.5$ & $1,683,198.2$ & $1,857,587.7$ & $2,474,095.1$ & $1,802,544.5$ & $1,820,179.2$ & $2,390,931.2$ & $3,128,121.7$ & $0.00 \%$ & $8.14 \%$ & $28.71 \%$ & $26.43 \%$ \\
\hline 15 & $3,806,510.6$ & $4,346,270.3$ & $4,623,046.5$ & $6,520,560.9$ & $3,806,510.6$ & $3,925,545.9$ & $3,411,319.2$ & $4,059,154.4$ & $0.00 \%$ & $-9.68 \%$ & $-26.21 \%$ & $-37.75 \%$ \\
\hline 16 & $3,253,464.8$ & $2,117,356.9$ & $3,919,772.3$ & $5,249,467.1$ & $3,253,464.8$ & $1,801,374.1$ & $2,623,141.2$ & $3,444,299.7$ & $0.00 \%$ & $-14.92 \%$ & $-33.08 \%$ & $-34.39 \%$ \\
\hline 17 & $7,687,645.8$ & $9,976,467.5$ & $13,241,356.9$ & $17,538,288.1$ & $7,687,645.8$ & $7,774,786.2$ & $6,367,764.4$ & $5,080,499.2$ & $0.00 \%$ & $-22.07 \%$ & $-51.91 \%$ & $-71.03 \%$ \\
\hline 18 & $846,442.1$ & $980,415.6$ & $1,159,682.8$ & $1,649,697.7$ & $846,442.1$ & $889,346.6$ & $919,499.1$ & $1,187,066.2$ & $0.00 \%$ & $-9.29 \%$ & $-20.71 \%$ & $-28.04 \%$ \\
\hline 19 & $20,289,800.9$ & $30,950,012.2$ & $38,922,961.0$ & $55,829,623.2$ & $20,289,800.9$ & $30,446,962.7$ & $37,115,657.9$ & $52,067,447.0$ & $0.00 \%$ & $-1.63 \%$ & $-4.64 \%$ & $-6.74 \%$ \\
\hline Total & $38,642,694.7$ & $51,739,728.6$ & $64,739,441.1$ & $90,946,162.2$ & $38,642,694.7$ & $48,097,248.9$ & $54,095,800.9$ & $70,887,419.0$ & $0.00 \%$ & $-7.04 \%$ & $-16.44 \%$ & $-22.06 \%$ \\
\hline
\end{tabular}

Table 11: Comparison between Scenario 1 and Scenario 3.

overcome this disadvantage and observe the dynamic relations of the industrial sectors.

Furthermore, based on the properties of influence and sensitivity analyses, we have conducted scenario analyses on three aspects: basic case, energy conservation, and carbon reduction. It has been shown that DIS can provide an analytical tool to initiate industrial policies which would facilitate a government to attain the aim of a win-win situation for the environment and the economy.

We have demonstrated the proposed system with the case of Taiwan. First, we have reclassified all industries into nine sectors of industries in interest: agricultural industries (I1), petrochemical mining industries (I2), metal and other mining industries (I3), agricultureprocessing product industries (I4), petroleum and carbon product industries (I5), metal and non-metal product industries (I6), electronic product industries (I7), electric, fuel gas and water supply industries
(I8) and service industries (I9) as shown in Table 2. We then employed DIS to forecast the industrial relations and states.

From the trend of demand and supply, we have observed that from the supply side, the ratio of the other input increases, while that of GDP decreases. In contrast, from the demand side, the ratio of intermediate demand decreases and that of final demand increases as shown in Table 3. This is a potential problem resulting in the decrease of our national output. Therefore, decreasing the energy and production dependency would be essential in avoiding the decrease of Taiwan's national output. In the meantime, the increasing ratio of final demand represents a good phenomenon, i.e., increased national production efficiency. The industrial structure also points out that the ratio of GDP for the agriculture, manufacturing, and service industries would be $0.75 \%, 37.86 \%$ and $61.39 \%$, respectively, by 2025 as shown in Table 5 .

From the influence and sensitivity analyses detailed in Figure 4, we realize that the metal and non-metal sectors (I6) are the key 
Citation: Wang HF, Lin D (2013) Dynamic Industrial System Approach to the Industrial Sustainability Development Based on National Economy-With a Case of Taiwan. Ind Eng Manage 2: 118. doi: 10.4172/2169-0316.1000118

and indispensable industries for economic development, while the agriculture-processing sectors, namely, the Agriculture-Processing Product Sector (I4) and Electronic Product Industries (I7) are important industries that can affect the growth of other industries. Including comparison based on Figure 4.

In summary, for the scenarios of energy conservation, we suggest the Taiwan government to increase the output of Petrochemical Mining Industries (I2) to balance the supply and demand of energy. For Taiwan, energy dependency is very high because of rare fossil energy. Therefore, the national government should increase energy efficiency and develop the technology of Petrochemical Mining Industries (I2) to gain a higher degree of energy security and sustainable development.

For the scenario of carbon reduction, policymakers may consider to regulate the manufacturing industry and promote the service industry to become the main economic industry with a high ratio of $73.45 \%$ by 2025 as shown in Table 10. At the same time, the agricultureprocessing product industries (I4), metal and non-metal product industries (I6) and electronic product industries (I7) can still play important roles because of their high degrees of influence. Increasing production efficiency in these sectors would be a good way to decrease carbon emission.

Future investigations covering the topics in practice below can be conducted as an extension of this study:

1. Add sample size to increase the lag period parameter $\mathrm{p}$ in the $\operatorname{VAR}(\mathrm{p})$ model and improve the accuracy of forecast.

2. Monitor both global and national environmental issues in order to develop updated strategies in the proposed DIS so that specific policies for industrial sustainability development can be evaluated and formulated.

\section{Acknowledgement}

The authors acknowledge the financial support from National Science Council with the project number NSC -98-2623-E-007-014-NU

\section{References}

1. William ER (1992) Ecological footprints and appropriated carrying capacity: what urban economics leaves out. J Environ Urbaniz 4: 121-130.

2. Chambers N, Simmons C, Wackernagel M (2000) Sharing Nature's Interest Ecological footprints as an indicator of sustainability. Earthscan, London.
3. Ming MW (2008) Integrating Green GDP with Input-Output Analysis for the Study of Eastern Region. Industrial Developments Essay of National Cheng Kung University Urban Planning in Taiwan

4. Jin W, Xu L, Yang Z (2009) Modeling a policy making framework for urban sustainability Incorporating system dynamics into the Ecological Footprint. Eco Econ 68: 2938-2949.

5. Jerzy A, Filar JB, Krawczyk (2010) Sustainability Screw Role of Relative Production and Abatement Time Scales: Preprint submitted to PNAS.

6. Leotief WW (1986) Quantitative input-output relation in the economic system of the United States: The Review of Eco and Stat XVIII 105-125.

7. Jung J J, Santos J R, Haimes YY (2009) International Trade Inoperability InputOutput Model IT-IIM: Theory and Application Risk Analysis 29: 137-154.

8. Crowther KG, Haimes YY (2010) Development of the Multiregional Inoperability Input-Output Model (MRIIM) for Spatial Explicitness in Preparedness of Interdependent Regions Systems Engineering 13: 28-46.

9. Karvetski CW, Lambert JH (2012) Evaluating deep uncertainties in strategic priority-setting with an application to facility energy investments Systems Engineering 15: 483-493.

10. Sheng CS (2007) Applied Time-Series Econometrics for Macroeconomics and Finance: Dong-Hua book store

11. Stock JH, Waston Mark W (2001) Vector auto regressions J Econ Persp 15: 101-115.

12. Danis K, Phillips PCB, Schmidt $P$, Shin $Y(1992)$ Testing the Null Hypothesis of Stationary against the Alternative of a Unit Root: J Econometrics 54:159-178.

13. Kmenta J (1997) Elements of Econometrics. (2nd edn), Macmillan Publishing Co, USA.

14. Enders W (2004) Applied Econometric Time Series. John Willey \& Sons Inc, USA

15. Non YY (2009) Time Series Analysis in Economics and Finance: Shuang Ye bookstore Co Ltd

16. Directorate-General of Budget, Accounting and Statistics. Executive Yuan ROC Website of green GDP.

17. Directorate-General of Budget, Accounting and Statistics. Executive Yuan $\mathrm{ROC}$ report of input and output analysis.

18. Box GE, Jenkins GM, Reinsel GC(1994) Time Series Analysis Forecasting and Control: $3^{\text {rd }}$ ed New Jersey SPrentice-Holland.

19. Bureau of Energy (2011) Ministry of Economic Affairs, Sustainable energy police convention.

20. Ministry of Economic Affairs (2010) National energy conservation and carbon reduction program. 